\title{
TADEYS DE OSVALDO LAMBORGHINI: CONSTRUCCIÓN DE UNA POÉTICA QUE DESESTABILIZA EL PATRIARCADO HETERONORMATIVO
}

\author{
TADEYS BY OSVALDO LAMBORGHINI: \\ A CONSTRUCTION OF A POETICS THAT DESTABILIZES \\ THE HETERONORMATIVE PATRIARCHY
}

Felipe Zúñiga Amaro

Universidad de Santiago de Chile. Santiago, Chile

felipe.zuniga.amaro@gmail.com

\begin{abstract}
Resumen: El estudio analiza las estrategias narrativas que conforman una poética que desestabiliza el patriarcado heteronormativo en la novela póstuma Tadeys (1983) de Osvaldo Lamborghini. Las estrategias desarticulan la concepción patriarcal del cuerpo, ya que es construido como un flujo de pulsiones donde se instalan subjetividades - prótesis artificiales- diseñadas por el Estado de La Comarca. Una de las estrategias narrativas es la confección de personajes masculinos motivados por impulsos primarios en un país patriarcal. En este sentido, el orden patriarcal se configura como una máscara cínica siempre transgredida por el deseo homoerótico de los ambivalentes personajes. La segunda estrategia narrativa es la deconstrucción del género femenino con la incorporación de la cárcel La Roca, espacio simbólico donde se transforma el cuerpo delictual masculino en una dócil mujer dispuesta al matrimonio. En esta cárcel el género femenino se representa y reproduce como performance, carece de una esencia a priori, puesto que es producto de instituciones que lo crean, reglamentan y naturalizan.
\end{abstract}

Palabras clave: Género, poética, patriarcado, estrategias narrativas.

\begin{abstract}
This study analyzes the narrative strategies that form a poetics that destabilizes the heteronormative patriarchy of the posthumous novel Tadeys (1983) by Osvaldo Lamborghini. The strategies disassemble the patriarchal conception of the body, as it is built as a flow of urges where subjectivities are installed -artificial prosthesis- designed by La Comarca State. One of the narrative strategies is the making of male characters motivated by primary drives in a patriarchal country. In this sense, the patriarchal order sets as a cynical mask always transgressed by the homoerotic desire of the ambivalent characters. The second narrative strategy is the deconstruction of the female gender with the incorporation of the prison La Roca, symbolic space where the male criminal body is transformed into a docile woman
\end{abstract}


ready to get married. In this prison, the female gender represents and reproduces as performance, it lacks of an essence $a$ priori, as it is the product of the institutions that create it, regulate it and naturalize it.

Keywords: Gender, poetics, patriarchy, narrative strategies.

Recibido: 25.08.2016. Aceptado: 20.12.2016.

\section{Introducción}

$\mathrm{L}$ A NOVEla PÓSTUMA Tadeys ${ }^{1}$-la única escrita por Osvaldo Lamborghini$\checkmark$ fue publicada por primera vez el año 1994 por Ediciones del Serbal en Barcelona. Esta heteróclita obra presenta múltiples historias, digresiones y temáticas circunscritas en La Comarca o LacOmar². La crítica especializada ha constatado que uno de los aspectos subversivos de la literatura experimental de Lamborghini es su intraducibilidad. En el preámbulo de la compilación de estudios críticos sobre su corpus literario, $Y$ todo el resto es literatura. Ensayos sobre Osvaldo Lamborghini (2008), se enuncia “[...] la imposibilidad de hacer presente el sentido de la literatura de Lamborghini como de explicar de manera suficiente su presencia en el presente" (Dabove y Brizuela, 2008: 20). Premat (2009) expresa que sus ininteligibles textos son "[...] reacios a todo discurso crítico, condenados a lo indecible" (141).

Considerando el problema descrito, la bibliografía crítica sobre Tadeys es exigua y se enfoca a interpretar, por un lado, qué significan los tadeys ${ }^{3}$;

${ }^{1}$ César Aira (2012) refiere que la novela Tadeys se inició en septiembre de 1983 y en diciembre del mismo año ya estaba terminada o bien interrumpida por otros proyectos escriturales. En el artículo se trabaja con la edición de Tadeys a cargo de César Aira.

${ }^{2}$ País imaginario de diez millones de kilómetros cuadrados, un poco más que la China. Es denominado de diversas formas porque Lamborghini juega con el lenguaje e imposibilita una representación unívoca (Rodríguez, 2008). Todas las historias (incompletas) de Tadeys convergen en el espacio de La Comarca, un Estado fascista regido por los Vomir, familia que monopoliza la carne de los tadeys, seres de ambigua caracterización, reproducidos y criados para que se transformen en mercancía. En cuanto al sentido de la novela, se adscribe a la perspectiva que despliega Montaldo (2008), quien la considera una "[...] fábula sobre el poder y la autoridad y [...] una ficción sobre las masas" (265). Por lo tanto, bajo esta óptica, narra el sueño de los Estados modernos por controlar las masas, simbolizadas con los tadeys.

${ }^{3}$ Las lecturas sobre el sentido de los tadeys son heterogéneas. Son interpretados como “[...] la masa anómala en el reino de la disciplina y el orden impuestos a través de la violen- 
por otro, a analizar la cárcel La Roca o máquina de amujerar ${ }^{4}$ y el tadey como representaciones de los diseños políticos orientados a controlar/homogeneizar las masas. En esta última línea se vincula el tadey con un pueblo animal que -en un marco biopolítico- representa los sujetos residuales de la sociedad, materia de experimentación/fabricación de cuerpos dóciles al Estado (Giorgi, 2008, 2014). Otra vertiente crítica -que indaga la arquitectura de la novela en relación a Rodolfo Walsh-, plantea que Tadeys es una ficción sobre los límites del lenguaje y representación, siendo su propuesta "[...] vaciar, destituir, evaporar las fijaciones de sentido, encarnando una grieta [...]" (Rodríguez, 2008: 180) que obstruye la representación en la literatura. En esta exégesis los tadeys "[...] son uno de los nombres para eso que hormiguea en el límite del lenguaje y que se resiste a su integración simbólica, a su inscripción representativa en alguna de las instituciones del sentido” (Rodríguez, 2008: 165).

cia represiva. [...] los excluidos y sumergidos que las clases políticas usan en su favor, de manera caníbal (son el alimento de los humanos), y sirven para hacer funcionar la economía del reino (son el nombre de la moneda). Clase sumergida, que se reproduce sin cesar y sirve de alimento a su amo, los tadeys son también un modelo para definir al enemigo" (Montaldo, 2008: 273). Además, son asociados al cruce entre el animal y el pueblo (Giorgi, 2014: 185). A pesar de devenir en un ser a-subjetivo (sin lengua) perseguido militarmente y deseado - es alimento y objeto de placer sexual de los poderosos-, "[...] funda el Imperio y el aparato estatal que lo sostiene" (Giorgi, 2014: 190). La Comarca se constituye una potencia dictatorial gracias a este tipo de comercialización. Rearticulando las miradas descritas, la perspectiva que se asume en el artículo comprende al tadey como ese otro despojado de subjetividad política y que contribuye al desarrollo del capitalismo siendo mercancía, por un lado; por otro, aquel que ha legitimado las prácticas sodomitas -entre machos o hombres, pues el narrador juega con la idea de los límites y el debate sobre la ontología del tadey- en su comunidad. En efecto, representan la sexualidad cínicamente prohibida y transgredida.

${ }^{4}$ En la cárcel-buque La Roca los hombres delictivos, homosexuales y enemigos del Estado son transformados en dóciles damas entregadas al cuidado del hogar y marido. Para ello experimentan un violento tratamiento cuya finalidad es fabricar cuerpos dóciles e ideales para el Estado de La Comarca. El proyecto se denomina Minones, una invenciónexperimento de los psiquiatras, el doctor Ky y Jones Hien. Así, La Roca es un espacio donde se construyen cuerpos artificiales e ideales para La Comarca -que en sí mismo no significan nada más que potencia de transformación-, mediante un experimento "[...] a cargo de figuras con poder y representantes del Estado [...]" (Giorgi, 2008: 240). En este lugar Lamborghini confronta la tradición política moderna para exhibir una política primitiva que carece de racionalidad y en la que sólo hay una lógica de dominación irracional (Montaldo, 2008: 267). 
Como contribución al escaso caudal bibliográfico sobre la novela, el presente artículo estudia las estrategias narrativas que configuran una poética ${ }^{5}$ desestabilizadora del patriarcado heteronormativo ${ }^{6}$ en Tadeys:

I. Una de las estrategias narrativas que subvierte el patriarcado es la confección de los personajes masculinos7 ${ }^{7}$ En esta lógica, la ley patriarcal, como impostura y máscara cínica -simulación de una heterosexualidad-, se diluye en los impulsos primarios de los personajes de La Comarca. Algunos personajes que escenifican la tensión entre el deseo y la ley son el sacerdote Maker quien, al contemplar a los tadeys, padece un culposo e ingente deseo sodomita; y relevantes figuras políticas masculinas que establecen un vínculo sexual secreto: Dam Vomir, alcalde de La Comarca, y Seer Tijuán, secretario de la Asesoría Legal, los cuales, sin embargo, se inscriben en la institución matrimonial, máscara con la que simulan una heterosexualidad ante la sociedad. En el apartado 1 se profundizan estas ambivalentes dinámicas rastreadas en varios personajes del enunciado literario.

${ }^{5}$ David Oubiña (2008) plantea que el corpus literario de Lamborghini constituye una poética: la función de la literatura es quebrar los modos de representación y la relación entre el lenguaje y la realidad (73). Tadeys adscribe a esta poética porque desestabiliza un sistema simbólico: el patriarcado heteronormativo. En cuanto al sentido de poética, asumiremos la perspectiva semiótica de Dolezel (1990), quien entiende las obras literarias como unidades semióticas complejas. Bajo este lineamiento, no sólo importa el sentido de Tadeys, sino también su forma o modalidad de construcción en función de un proyecto literario, dislocar los modos de representación. Por ende, los temas y la lengua, material de la literatura, son un material que "[...] se transforma en una estructura poética a través de la forma, que Mukarovsky especifica como operación conjunta de dos procedimientos: la deformación y la organización" (Dolezel, 1990: 217). La forma de Tadeys, articulada por estrategias narrativas -construcción de personajes y espacio-, conforma una poética específica que quiebra los modos de representación del patriarcado heteronormativo.

${ }^{6}$ Por patriarcado heteronormativo se entiende el modo de representación erigido en base a una ley paterna que distribuye los roles géneros, legitima la heterosexualidad y prohíbe la homosexualidad. Desde el orden simbólico patriarcal la homosexualidad queda conminada y negada, puesto que "[...] se considera que la especificación ontológica del ser, la negación y sus relaciones están expresadas por un lenguaje articulado por una ley paterna y sus mecanismos de diferenciación" (Butler, 2007: 115).

7 Premat (2009) estudia el cinismo de los personajes de Lamborghini -cuyo único motor son los impulsos primarios- en vinculación intertextual con Lacan y Macedonio Fernández. 
II. Como segunda estrategia, el narrador incorpora el espacio simbólico y polisémico de la cárcel-buque La Roca, lugar que tiene una doble funcionalidad:

1) La cárcel aísla al sujeto problemático de La Comarca. El uso del buque como espacio de exclusión del otro es simbólico y tiene resonancias históricas, pues en Occidente los sujetos molestosos e innecesarios para el diseño social eran abandonados en el mar en una nave. Foucault analiza este tipo de confinamiento en Historia de la locura en la época clásica (1967), basándose en la representación pictográfica y literaria de La nave de los locos del siglo XV. Así, el uso de este espacio representa en el texto el poder que tiene el Estado para excluir a los sujetos que no encajan en sus criterios de sociabilidad.

2) El narrador deconstruye la heteronormatividad, explicitando que en la cárcel-buque La Roca se fabrica -con el cuerpo de los reclusos- una mujer sumisa dispuesta al matrimonio mediante el tratamiento Minones. La voz narrativa describe las etapas del tratamiento, dispositivo que construye la matriz de la heteronormatividad. De modo que el género femenino se representa como una construcción cultural que no responde a ninguna esencia, sino más bien es producto de instituciones que lo crean, reglamentan y naturalizan mediante la violencia.

Respecto a la deconstrucción del patriarcado heteronormativo, el binomio hombre/mujer se quiebra pues Tadeys narra sobre un cuerpo sin esencia ni sustancia a priori, sino más bien producto de intervenciones de poder que crean la ilusión de una metafísica de la presencia, es decir, de una heteronormatividad natural. En efecto, en Tadeys opera una perspectiva de género femenino como performance, como imitación de ciertos actos inscritos en la cultura, los cuales son prótesis violentamente instaladas en la institución carcelaria. En la novela se produce el desplazamiento del género sexual: los reclusos devienen en dóciles damitas dispuestas al matrimonio pero poseen miembro masculino. Sin lugar a dudas, se resquebraja el binomio masculino/femenino y se invierten las oposiciones clásicas de representación con este cuerpo informe ${ }^{8}$.

${ }^{8}$ La deconstrucción como estrategia filosófica o estrategia para tratar a la filosofía opera por medio de la inversión de oposiciones binarias y un desborde de los sistemas 
La exégesis se desglosa en dos apartados. En el primero, se rearticulan algunos aportes bibliográficos sobre la poética de Lamborghini. Luego se analiza la estrategia narrativa -confección de personajes motivados por impulsos primarios- que transgrede al patriarcado en función de la poética del argentino En el apartado siguiente se indaga la segunda estrategia narrativa que subvierte el patriarcado heteronormativo: la construcción del espacio simbólico de la cárcel La Roca, el cual funciona como una zona de poder donde el género femenino es construido artificialmente mediante la obligación a repetir pautas de comportamiento preestablecidas. Se deconstruye, en consecuencia, una heteronormatividad natural al presentar el cuerpo como soporte donde se instalan significados -prótesis- desde el poder coercitivo de La Comarca.

\section{El personaje masculino patriarcal y cínico de La Comarca}

En este apartado se aborda una de las estrategias narrativas que desestabiliza el patriarcado heteronormativo en La Comarca. La estrategia consiste en la construcción de personajes masculinos que funcionan como flujo de deseos no subordinados a reglas culturales, los cuales manifiestan un homoerotismo. Es decir, son personajes motivados por impulsos primarios, y sobre ellos se proyecta la máscara cínica del orden patriarcal. Ni autoridades eclesiásticas logran reprimir sus impulsos primarios, pues la ley cultural se disuelve en el deseo sodomita. Premat (2009) enuncia que una cualidad representativa de los textos de Lamborghini es "[...] un cinismo radical que convierte todo en asuntos pulsionales" (140).

Antes de abordar la estrategia narrativa descrita, resulta imprescindible rearticular la bibliografía que versa sobre la poética de Lamborghini. La configuración de su poética apunta a desestabilizar los sistemas simbólicos, construidos por una lengua vinculada a la coerción y dominación de lo real. La poética se describe minuciosamente en la revista Literal $^{9}$.

de representación, vale decir, "[...] por medio de una acción doble, un silencio doble, una escritura doble, poner en práctica una inversión de la oposición clásica y un corrimiento general del sistema" (Culler, 1984: 79).

${ }^{9}$ La revista Literal, creada en 1973, fue "[...] uno de los proyectos literarios más intensos y revulsivos de la historia cultural argentina [...] quedó inscripta en la memoria 
David Oubiña (2008) asevera que Lamborghini inaugura con El fiord una poética opuesta al realismo y la concepción instrumental de la literatura, siendo Literal el soporte textual que la posiciona dentro del campo cultural argentino: “[...] Literal repone la opacidad propia del lenguaje (su sobreabundancia) que el discurso realista intenta ocultar. Ese carácter no instrumental defendido por la revista supone una voluntad de expresar en las palabras la inadecuación entre literatura y realidad [...]” (Oubiña, 2008: 73).

La perspectiva crítica del lenguaje y la representación de la realidad (como poder) son temas literarios relevantes en los materiales estéticos de Lamborghini. La crítica ha sostenido que Lamborghini subvierte la lengua y los sistemas de representación mediante el uso del cuerpo como soporte que instala las tensiones políticas de poder. Todo orden institucional y político (lingüístico) funciona mediante la coerción y violencia, expresada con la sodomía y un esquema de poder articulado en base al binomio activo/ pasivo. Así se pone en evidencia un aspecto primitivo e irracional de la política y se fracturan los sistemas de representación racionales. Respecto a El fiord, Oubiña (2008) enuncia que su lengua política “[...] es su lenguaje de los cuerpos [...]. Las cópulas son alianzas ideológicas. Y viceversa. Todo debe entenderse en un doble sentido, a la vez político y sexual” (74).

Tadeys es coherente con la poética descrita, principalmente, con la estrategia narrativa que hace uso del cuerpo como soporte de las tensiones políticas, materializadas con la sodomía. En la diégesis, una estrategia narrativa que fractura el orden patriarcal, entendido como construcción lingüística, es la confección de personajes que funcionan como flujo caótico de deseos sexuales. Bajo esta lógica, el patriarcado carece de sustrato

cultural argentina como la propuesta más ajustada en pos de la vanguardia estética y de la autonomía literaria y en contra de la ilusión referencial” (Rosano, 2008, p. 203). Además, en sus dos primeros años de circulación "[...] arremete con mucha fuerza contra lo que llama "la ilusión populista", específicamente contra el populismo latinoamericanista de la revista Crisis [...]" (Rosano, 2008: 203). En Literal se aboga por "[...] una escritura que se desentiende de todo "compromiso" en términos de representación (denuncia realista de la explotación, representación de las luchas sociales), pero que por eso mismo deviene inmediatamente política, en tanto ejerce una política (transgresora, revolucionaria) de la lengua [...]. Al negar todo intento de verosimilitud realista, el lenguaje poético desmontaría críticamente la ilusión de una correspondencia posible entre las palabras y las cosas" (Peller, 2005: 105). En Literal se constata que los fenómenos de la cultura son construcciones lingüísticas, representaciones verbales de poder y dominación. 
metafísico y verdad: es sólo un orden lingüístico autoritario, una forma de inventar lo real. En La Comarca la homosexualidad es prohibida, pero la norma es asiduamente transgredida por los cínicos personajes masculinos. Según Premat (2009) en la literatura de Lamborghini lo único real es el goce y las reglas culturales son mera virtualidad: "[...] hay una insistente proyección de valores, discursos, instituciones, tradiciones, cultura, hacia otro lado, hacia una cara oscura que sería la de la pulsión, única ley y motor de las acciones humanas [...]" (Premat, 2009: 141).

Bajo este lineamiento, Mikel Imaz (2005) plantea que "[...] el homoerotismo permea toda la realidad social de La Comarca" (131), deconstruyéndose el supuesto de verdad de la masculinidad. La institución patriarcal es transgredida por personajes permeados por un deseo homoerótico, motivados sólo por los impulsos primarios; diluyéndose no sólo la ficción de la masculinidad patriarcal, sino también toda institución. Este patriarcado es enunciado genealógicamente, aunque en la ficción la estructura temporal es desordenada. Las discontinuidades sociales del país están signadas desde el origen por la sodomía como una forma de establecer relaciones jerárquicas de poder entre hombres en un mundo profundamente misógino.

El punto de emergencia de La Comarca es la Edad Media, pero el grueso del relato funciona con instituciones modernas (Montaldo, 2008, p. 265). Un personaje paradigmático que escenifica la tensión entre la ley (patriarcal) y el deseo, como estrategia narrativa, es el sacerdote Maker. En la Edad Media fue exiliado por hereje, ya que había traducido la Biblia a la lengua de La Comarca y el resultado fue un texto pornográfico. La autoridad eclesiástica, en su exilio, encontró en las zonas del norte de La Comarca una caverna habitada por unos singulares seres que denominó Tadeus, Tadeos o Tadeys. Con mirada de antropólogo, fue inquiriendo gradualmente en su complejo entramado de interacciones sociales y de poder. Producto de su tesón y arduas indagaciones pudo interpretar que eran una especie de simios sin pelos, que durante el día tenían relaciones sodomitas entre machos y, durante la noche, fornicaban con hembras sólo para conservar la especie. Quien detentaba el poder en aquella tribu era un viejo que tenía la mayor capacidad para ser sodomizado. El cínico sacerdote Maker construye lingüísticamente una idea negativa del tadey, a pesar de sodomizar con intensa delectación al Gran Tadey, líder de esta comunidad. La primera vez que Maker atisbó a un tadey, se fijó en sus nalgas con un sentimiento de 
culpa: “[...] Maker pensó en azotarse esa misma noche, en cuanto se quedara solo: eran perfectas las nalgas de Tadey, encendían el deseo, a cualquiera eran capaces de enloquecer (iazote!), a personas más frígidas que él” (188). Este segmento narrativo expresa la artificialidad de la ley del orden simbólico patriarcal, pues siempre es transgredida por el deseo, impulso que desborda las normas culturales (Rodríguez, 2008, p. 176).

Otro personaje que expresa el cinismo de la ley patriarcal en la Edad Media es el militar Taxio Vomir, sodomita empedernido. Considerando que en La Comarca la homosexualidad es prohibida, escribe la Obra magna e informa rigurosamente que el tadey es un animal mamífero sodomita. El militar es condenado a la hoguera por su blasfemia. Conjuntamente, los tadeys son excluidos de los registros lingüísticos (diccionarios). Paradójicamente, los descendientes de su familia, la dinastía Vomir, monopolizan la comercialización de la carne del tadey, cimentándose un país cuya riqueza depende de esta. En La Comarca moderna, todos los hombres patriarcales desean sexualmente a los tadeys, animales de horrible rostro, pero de contorneadas nalgas.

Otro caso paradigmático que ilustra la dinámica descrita es la historia patriarcal del cabrero Kab, un hombre muy pobre y autoritario que emigra del campo a la ciudad con su esposa e hija, ambas azotadas por querer desobedecer su palabra. Antes del periplo, el cabrero sodomiza a un niño de once años, un boyerito a quien no ama y usa como objeto de fruición sexual. Después de sufrir una violenta penetración y felación, el boyerito, atribulado, murmulla sobre los hombres que "Lo único que quieren es coger, y luego abandonan a su suerte a la pobre desgraciada” (29). El niño, al representarse como mujer, construye la ilusión de la heterosexualidad. Además, la idea que construye del hombre y la mujer corresponde a los estereotipos heterosexuales del "novelón radial" (29); injertos que se instalan en la subjetividad del personaje como modelos artificiales de lo real. En la novela es el bujarrón, el penetrador, quien tiene el poder sobre el pasivo (marica), desvelándose un deseo homoerótico que es disfrazado con "El rito de la heterosexualización de la relación sexual entre dos hombres y la consiguiente feminización de uno de los actantes" (Imaz, 2005, p. 137). Así, se oculta la homosexualidad (latente) bajo la máscara del patriarcado, construcción cultural cínica.

Otro ejemplo representativo del patriarcado como impostura, es el caso 
de Dam Vomir, alcalde de La Comarca, y Seer Tijuán ${ }^{10}$, primer secretario de la Asesoría Legal. Ambos personajes masculinos establecen un vínculo sexual oculto, pero están casados y tienen hijos, siendo la institución matrimonial una máscara hueca con la cual se presentan en sociedad según lo amerite. El diálogo entre ambos sujetos -en un decadente restauranteexplicita la idea esbozada con cierta tensión y cinismo: “[...] Dam había cometido un error. Le contó que se había casado en Francia y que tenía - y no le importaban, como tampoco la madre - dos hijos, cuya edad ni siquiera recordaba" (131).

El diálogo desemboca violentamente: Dam abofetea con vehemencia a Seer por celos. Posteriormente, la víctima se embriaga en un tugurio astroso y busca servicio sexual masculino en un sitio baldío, trocando su nombre por Melita. El prostituto que lo penetra, nominado Bicho, le dice con animadversión, posterior al acto, que lo deje solo, pues saldrá con una mujer que desconoce su menester: "[...] Mirá puto, una de dos, o te vas o te rompo la cara. A la vuelta de la esquina me espera una hembra que no sabe que ando en el negocio. ¿Qué querés, que te la presente?” (137). Sin lugar a dudas, Bicho quiere encajar en el marco de la heterosexualidad para presumir masculinidad en su cita; Seer Tijuán procede de forma análoga al cambiar su nombre por Melita y comportarse como las románticas mujeres de los novelones radiales.

Tadeys conforma una poética que desestabiliza el patriarcado heteronormativo, puesto que deja en evidencia su virtualidad. La única motivación de los personajes son pulsiones que asiduamente lindan con un homoerotismo disimulado. El cabrero Kab, el sacerdote Maker, el militar Taxio Vomir, Seer Tijuán y Dam Vomir encarnan una máscara patriarcal, simulan una heterosexualidad en base a una ley simbólica que se diluye en el deseo. Es por ello que estos personajes son, principalmente, el despliegue anárquico de impulsos primarios que desbordan todo marco cultural y desmontan las ficciones que se han erigido sobre lo masculino.

\footnotetext{
${ }^{10}$ Seer Tijuán fue un niño de humilde familia y escolar destacado, que recibe constantes ignominias de sus compañeros -poemas con rimas ofensivas: “Tijuán, Tijuán, por el Culo te la dan" (37) - y golpizas por parte de su padre. Seer es educado por dos modelos de realidad en tensión: su padre quiere transformarlo en un hombre macho; su madre añora que sea un homosexual delicado -y pasivo- que enamore a un poderoso. Finalmente, triunfa el modelo maternal: cuando Seer es adulto logra trabajar para Dam Vomir, alcalde de La Comarca, con el cual establece un vínculo de relaciones sexuales jerárquicas.
} 


\section{Centro de reclusión La Roca: el género femenino como construcción artificial}

Otra estrategia narrativa que subvierte el patriarcado heteronormativo es la construcción del espacio simbólico de la cárcel-buque La Roca. Tadeys configura una poética que desestabiliza el patriarcado heteronormativo, pues desmantela la ficción de una heterosexualidad natural y narra la presencia de un cuerpo que en sí mismo nada significa, que es potencia de transformación y flujo de pulsiones ${ }^{11}$. Esta potencia de devenir la manipula el Estado para diseñar cuerpos heterosexuales ideales y disciplinados en La Roca ${ }^{12}$.

En La Roca, transatlántico alejado a unas cuantas millas del puerto de La Comarca, actúa el poder psiquiátrico con un experimento que pretende transformar el cuerpo del joven delictual en una dulce damita dispuesta al matrimonio. Este se denomina Minones, cuyo nombre oficial es "Método para dulcificar las costumbres de adolescentes violentos” (75). El pendenciero violento: “[...] era transformado en mujer, en una damita deliciosa, que era pedida en matrimonio a veces, o si decidía vivir sola o con su ama de llaves, no era infrecuente que hiciera correr sangre entre los hombres $[\ldots] "(75)$.

Aquel perímetro de disciplinamiento recibe incesantemente presos gracias a una estricta vigilancia de la policía, la cual efectúa razzias en los centros de entretención nocturna para así localizar los hombres iracundos,

\footnotetext{
${ }^{11}$ Cabe señalar que la interpretación se ciñe a lo que dice el texto literario sin imponer una clave exegética en boga que explique su sentido. En la cárcel La Roca de Tadeys el cuerpo es materia de experimentación y transformación por parte de autoridades estatales. En esta dirección, la novela exhibe el género sexual como virtualidad y construcción política. Así mismo las características del enunciado literario permiten establecer una fructífera relación con algunos exponentes -Foucault y Butler, por ejemplo- que reflexionan sobre el cuerpo y el poder.

${ }^{12}$ En Tadeys el orden sexual heteronormativo no responde a ninguna verdad, es un discurso y experimento del psiquiatra, el doctor Ky. Aquel personaje confecciona el preámbulo para su obra "El Estado Espejo y su Orden Sexual" (98) en su diario de vida. En este soporte textual reflexiona sobre las prácticas correctivas para erigir el orden sexual heteronormativo, un orden discursivo. El análisis descrito se afinca desde el enunciado literario, no pretende ilustrar una teoría con el uso del concepto heteronormativo. Una de las funciones de la crítica literaria es traducir la obra al lenguaje de la teoría. Bajo este ángulo la lectura no emerge desde una teoría, los rasgos específicos del material estético determinan la teoría y el método conveniente.
} 
homosexuales y enemigos del Estado ${ }^{13}$. En la comisaría el forense Vich examina a los detenidos y "[...] si les encontraba síntomas pendencieros asociales, luego de depilarles todo el cuerpo, eran alojados en el barco" (76). Este tipo de confinamiento y control del otro que se considera loco o molestoso para la sociedad fue analizado por Foucault en Historia de la locura en la época clásica (1967), basándose en la representación pictográfica y literaria de La nave de los $\operatorname{locos}^{14}$ que eclosiona en los últimos años del siglo XV.

${ }^{13}$ El contexto histórico-político construido en el enunciado literario no es el foco de este artículo. Sin embargo sería valioso indagarlo considerando la poética de Tadeys, enfocada a quebrar la relación entre las palabras y el referente. Sin lugar a dudas la novela no aspira a una ilusión referencial ni a una representación simbólica de las problemáticas políticas de Argentina, puesto que la obra de Lamborghini es "[...] una literatura antirrealista [...], que en el país de la representación (la Argentina peronista era ya una representación) [...] opone, a la representación de la realidad, la realidad material de la representación [...]" (Rodríguez, 2008: 160). En el segmento citado se puede dilucidar que Tadeys -como todo el corpus literario de Lamborghini- desmonta la representación de la realidad y fractura el efecto de ilusión referencial. Algunos estudios interpretan desacertadamente La Comarca como representación de la Argentina, obviando la compleja poética del discurso literario. En esta línea Imaz (2005) atisba en la ficción una relación entre La Comarca y la historia política de Argentina: "[...] podría establecerse una lectura macrohistórica de la Argentina, desde el período colonial con el Santo Oficio como guardián celoso de las tradiciones religiosas y civiles, pasando por las guerras civiles posteriores a la independencia argentina en el siglo XIX y la prosperidad que la exportación de la industria agropecuaria aportó a la Argentina a finales del siglo XIX y comienzos del siglo XX, para culminar con el régimen represivo de la última dictadura [...]" (131). Fácilmente podría conjeturarse la idea esbozada en el fragmento -es decir, suponer erradamente que La Comarca es una representación de Argentina-, ya que la obra literaria presenta un país ficticio caracterizado por la persecución política propia de la dictadura y, conjuntamente, su éxito económico se debe a la exportación de carne del tadey. Pero La Comarca, a pesar de tener rasgos que puedan asociarse a la historia de Argentina, es un país que juega con la ilusión referencial y dinamita la posibilidad de generar un efecto de realidad con la presencia de los tadeys. Aquellos seres inclasificables -el narrador nunca deja claro si son humanos o animales: "[...] parecían hombres, parecían tener la capacidad de concentrarse" (215)- encarnan este quiebre. Ante la problemática descrita subyace la necesidad de rearticular los enfoques críticos para abordar el contexto histórico-político que construye el enunciado literario no sólo de Tadeys sino de toda la producción escritural de Lamborghini.

${ }^{14}$ Sebastián Brant creó una obra satírica y moralista denominada La nave de los locos (1494) que critica los vicios de su época, adjuntando grabados que complementan el discurso escrito. Los locos reclutados en los barcos eran objeto de un sistema de exclusión de los márgenes de la sociedad, como una forma sofisticada de confinamiento. Encerrado en el navío "[...] es el pasajero por excelencia, o sea, el prisionero del viaje. No sabe en qué tierra desembarcará; tampoco se sabe, cuándo desembarca, de qué tierra viene" (Foucault, 1967: 19) y "[...] en ciertas ciudades importantes [...] los locos eran llevados en número considerable por marineros y mercaderes, y que allí se "perdían", librando así de su presencia a la ciudad de donde venían" (Foucault, 1967: 23). Aquellos eran condenados al exilio perpetuo por no encajar en los criterios de normalidad. Los navíos en que eran relegados eran "altamente simbólicos" (Foucault, 1967: 23), ya que los conducían a la búsqueda de la razón, considerando que en la época había una correlación entre el agua y la cura de la locura. 
Indudablemente en Tadeys el buque-cárcel, espacio ligado a un imaginario histórico, posee la función de excluir socialmente a quien se considera un problema pero para disciplinarlo e integrarlo a la comunidad. En la ficción la perspectiva es disímil y abstrusa, aunque sí resemantiza un espacio históricamente asociado a la exclusión social. El buque-cárcel de la novela contiene rasgos que le confieren mayor complejidad y espesor semántico, puesto que simboliza, además, un espacio que reproduce la mujer que encaja en el orden heteronormativo. Foucault señala respecto al confinamiento que "[...] ha sido desde el comienzo una "detención legal" encargada de un suplemento correctivo, o también, una empresa de modificación de los individuos que la privación de la libertad permite hacer funcionar en el sistema legal" (Foucault, 2002: 235). Bajo esta mirada, la ley es la fuerza que crea los parámetros de un modelo de realidad arbitrario: en el caso de la novela, la producción masiva de cuerpos ideales en La Comarca.

Al final del capítulo I el narrador enuncia fragmentariamente el proceso/tratamiento que experimentan los reclusos. Este tratamiento se compone de dos etapas cabalmente supervisadas que quiebran el supuesto ficticio de una heteronormatividad natural.

En la primera etapa los convictos son sodomizados por bufas ${ }^{15}$ durante una semana sobre la inmensa cubierta del transatlántico. Aquella práctica de control es realizada a la luz del día, hacinados intencionalmente para que los penetradores intercambiaran al convicto, premiándose al penetrador incansable, apodado Búfalo Bill. En esta etapa del procedimiento, todos los sodomizados comparten colectivamente su situación de subordinación. Las figuras institucionalizadas de control y poder crean la ilusión de que aquella situación es normal. Una vez culminada la sodomía, los reclusos reciben una salvaje golpiza y una amenazante amonestación: “[...] no te olvides, piba, desde hoy éste es tu culo rendido a un hombre, es tu único órgano sexual. Ya no es tuyo. Es tu Yo" (78).

A partir del segmento narrativo, se puede constatar una crítica al sistema de reproducción heteronormativo, no atisbado como un orden natural, sino más bien como un constructo cultural mediado por instituciones que tienen el poder de disciplinar. A través del castigo y la violencia física se

${ }_{15}$ El significado que se le atribuye al concepto bufa está inscrito en el lunfardo, que significa un sujeto que gusta de copular o violar a varones. 
fuerza a los convictos a ser pasivos, ya que el doctor Ky crea un método de control denominado pescabufines, una sustancia sintética inoculada en el ano de los encarcelados que delataba si habían penetrado o no: "Cada media hora todos eran obligados a formar y mostrar su pene: el que la tenía moteada de pintitas blancas (sólo visibles con microscopio) era picaneado de inmediato en el recto, puesto que las manchas [...] lo denunciaban" (77). Quienes infringen las reglas -la homosexualidad es prohibida en La Roca- son torturados diez minutos con la picana eléctrica en la "Cámara Especial".

Resulta ubérrimo indicar que el doctor Ky, un psiquiatra, es quien participa de la invención del proyecto Minones. Su campo del saber, la psiquiatría, es una disciplina que en sus inicios, cuando delimitó su objeto de estudio y devino científica, clasificó al homosexual como anormal ${ }^{16}$. En Tadeys el doctor Ky ejerce el poder de prohibir la homosexualidad dentro del transatlántico, desplegándose una alusión al discurso psiquiátrico que intentó naturalizar la heterosexualidad. Este discurso se configura como una construcción violenta y excluyente del sujeto homosexual, por ende no está disociado del poder. Sobre el sentido del discurso psiquiátrico como saber/experimento intrínsecamente ligado al poder, Giorgi (2008) señala que construye "[...] las posibilidades mismas de lo viviente [...]" (240-241). En la novela el diario de vida del doctor Ky -donde registra las prácticas correctivas- viene a confirmar la idea de que el orden heterosexual es una creación artificial-lingüística, por un lado; y por otro, describe las tecnologías correctivas de prácticas sexuales que desbordan el marco del modelo heterosexual, lo cual implica que el saber es indisociable del poder. En consecuencia, Tadeys despliega la imagen de una heteronormatividad virtual, naturalizada y legitimada por el saber científico.

\footnotetext{
${ }^{16}$ Michel Foucault en su obra Los anormales explora las relaciones entre el saber médico psiquiátrico y el poder social. A partir de distintas fuentes médicas, jurídicas y teológicas, analiza a aquellos sujetos peligrosos que en el siglo XIX eran catalogados de anormales. Aquellos eran los monstruos, los incorregibles y los onanistas. Dentro de la categoría del individuo a corregir, se encontraban los homosexuales y los bisexuales en el siglo XVIII, los cuales eran sometidos a la prohibición como mecanismo normalizador: "La prohibición constituía la medida judicial mediante la cual se descalificaba a un individuo, al menos parcialmente, como sujeto de derecho. Ese marco jurídico y negativo, va a ser en parte cubierto y en parte remplazado por un conjunto de técnicas y procedimientos con los que se emprenderá el enderezamiento de quienes se resisten a la domesticación y la corrección" (Foucault, 2007: 298).
} 
La segunda parte del tratamiento consiste en la enseñanza de los modales y comportamientos femeninos, es decir, la construcción del género femenino. Para tal designio, el barco contaba con un equipo altamente calificado: “[...] putas de alto vuelo, famosos travestis, lesbianas activas [...]. Ky y Jones querían fabricar damas para todos los gustos, muñecas que no fallaban nunca, en ninguna circunstancia” (76).

En Tadeys se constituye una noción de género femenino como construcción cultural mediada por un entorno coercitivo. La voz narrativa ahonda esta idea cuando enuncia mordazmente que "[...] las celdas se transforman en coquetos camerinos" (87), y respecto a la vestimenta masculina, "[...] era sustituida por hermosos y refinados vestidos de mujer, sin olvidar los elementos de maquillaje" (88). Además, el buque cuenta con todo un equipo para reforzar el género femenino en el tratamiento: "[...] nubes de peluqueros, manicuras, masajistas, especialistas en belleza, dietólogos y [...] bufas, todos a su disposición” (89). Las futuras damitas se atribuyen, también, un período de tiempo de siete días, denominado "Gorjeo carnal y espiritual”, en que pueden escoger a quien las posea sexualmente. En ese contexto, entrenan sus capacidades de seducción femeniles con otros hombres, no necesariamente los bufas.

Bajo esta dinámica, la fabricación de damitas mediante el tratamiento viene a ratificar que el género es una práctica encarnada, un conjunto determinado de acciones que se dan en un individuo con una frecuencia sostenida, de modo que nunca estaríamos denotando una esencia natural a priori sobre ser mujer ${ }^{17}$. Las damitas aprenden su rol mediante diversos factores externos institucionalizados, fomentando un vestuario específico,

${ }^{17}$ En Tadeys la mujer dócil fabricada en La Roca no tiene esencia, sino más bien es producto del contexto social y su identidad de género es sólo la repetición de actos performativos desplegados en un espacio. De modo que el género femenino, en la novela, se mantiene a partir de la repetición de comportamientos preestablecidos que generan la ilusión de una sustancia o metafísica de la presencia. La concepción de género sexual que subyace al enunciado literario dialoga con la perspectiva de Butler, quien aboga por una concepción de género carente de esencia y sustancia: "Este planteamiento aleja la concepción de género de un modelo sustancial de identidad y la sitúa en un ámbito que exige una concepción del género como temporalidad socialmente constituida. Resulta revelador que si el género se instaura mediante actos que son internamente discontinuos, entonces la apariencia de sustancia es exactamente eso, una identidad construida, una realización performativa en la que el público social mundano, incluidos los mismos actores, llega a creer y actuar en la modalidad de la creencia” (Butler, 2007: 274). 
desear hombres y asumir roles relacionados con el cuidado del hogar y matrimonio. En efecto, el transatlántico es un dispositivo que origina prácticas de deseo y roles de género orientadas a la creación del mundo virtual de la heteronormatividad como estrategia de control político.

Aquella mujer originada en la cárcel-buque no es natural ni tiene esencia, sólo es una invención de la cultura masculina falocéntrica, simbolizada en las figuras perversas del doctor Ky y Jones Hien. Estos desquiciados personajes representan la ideología patriarcal. Así, “[...] la genealogía masculina es una institución específicamente cultural y que se constituye como un orden simbólico estructurado en base al Nombre del Padre, que funciona como pivote del sistema" (Amorós, 1991: 67). La cárcel La Roca funciona como una metáfora que expresa la reproducción performativa del sistema heteronormativo, es decir, una sociedad con mujeres profundamente sumisas.

En conclusión, la novela póstuma de Lamborghini constituye una poética desestabilizadora del patriarcado heteronormativo. Las estrategias narrativas que constituyen una poética específica -construcción de personajes motivados por pulsiones e integración de un espacio simbólico (La Roca) que deconstruye el género femenino- dan cuenta de que el cuerpo está despojado de un sentido trascendental, es potencia de devenir -flujo de pulsiones- y producto de los mecanismos de disciplinamiento de La Comarca, los cuales diseñan cuerpos ideales para el Estado. La Comarca fabrica roles de género y los sostiene sin un proceso democrático, sino más bien por la obligatoriedad a la performatividad, por un lado; y, por otro lado, por la obediencia a la ley. En Tadeys, por lo tanto, se deconstruye la naturalidad de la matriz heterosexual, quedando en evidencia que la construcción cultural del género se ha mantenido a través de mecanismos homogeneizantes. En la novela hay una crítica a los modos de representación del cuerpo -ceñidos al patriarcado heteronormativo-, ligados al poder e invención arbitraria de lo real. Premat (2009) afirma que la literatura cínica de Lamborghini, al igual que el modelo de saber lacaniano, “[...] deja de tener visos de verdad o de recurrir a una voluntad de verdad socialmente codificada, para dejar ver las fallas, las dudas, la incertidumbre" (160). Paradójicamente la traducción de Tadeys al lenguaje de la teoría transforma la incertidumbre en una verdad socialmente codificada. Esta ambivalencia es necesaria porque suscita nuevas lecturas sobre un material estético complejo y reacio a ser descifrado. 


\section{Referencias}

Aira, C. (comp.). (2012). Nota del compilador. En O. Lamborghini, Tadeys (pp.7-11). Buenos Aires: Mondadori.

Amorós, C. (1991). Hacia una crítica de la razón patriarcal. Barcelona: Editorial del hombre.

Butler, J. (2007). El género en disputa. Barcelona: Paidós.

Culler, J. (1984). Sobre la deconstrucción. Teoría y crítica después del estructuralismo. Madrid: Cátedra.

Dabove, J. y Brizuela, N. (comps.). (2008). Introducción. En $Y$ todo el resto es literatura. Ensayos sobre Osvaldo Lamborghini (pp. 9-30). Buenos Aires: Interzona.

Dolezel, L. (1990). Historia breve de la poética. Madrid: Editorial Síntesis.

Foucault, M. (1967). Historia de la locura en la época clásica. Tomo 1. Buenos Aires: Fondo de Cultura Económica.

. (2002). Vigilar y castigar. Buenos Aires: Siglo XXI Editores Argentina. . (2007). Los anormales. Buenos Aires: Fondo de Cultura Económica.

Giorgi, G. (2008). El crimen, el experimento, la literatura: Osvaldo Lamborghini y la naturaleza. En J. Dabove y N. Brizuela (comps.), Y todo el resto es literatura. Ensayos sobre Osvaldo Lamborghini (pp. 233-253). Buenos Aires: Interzona.

. (2014). Ese pueblo que nunca dejará de ser animal: Osvaldo Lamborghini. Formas comunes: animalidad, cultura y biopolítica (pp. 169-194). Buenos Aires: Editorial Eterna Cadencia.

Imaz, M. (2005). Analidad, deseo homoerótico y (de) construcción de la masculinidad en Tadeys de Osvaldo Lamborghini. Chasqui: Revista de Literatura Latinoamericana, 34, 130-141.

Lamborghini, O. (2012). Tadeys. Buenos Aires: Mondadori.

Montaldo, G. (2008). La ficción de las masas. En J. Dabove y N. Brizuela (comps.), Y todo el resto es literatura. Ensayos sobre Osvaldo Lamborghini (pp. 255-277). Buenos Aires: Interzona.

Oubiña, D. (2008). De la literatura entendida como delirium tremens. En J. Dabove y N. Brizuela (comps.), Y todo el resto es literatura. Ensayos sobre Osvaldo Lamborghini (pp. 71-93). Buenos Aires: Interzona.

Peller, D. (2005). Estertores de una década: Josefina Ludmer y Osvaldo Lamborghini en Babel a fines de los 80. Revista del Centro de Letras Hispanoamericanas, 17, 97-109.

Premat, J. (2009). Lamborghini: Lacan con Macedonio. Héroes sin atributos. Figuras de autor en la literatura Argentina (pp.135-166). Buenos Aires: Fondo de Cultura Económica.

Rodríguez, F. (2008). Escribir afuera: literatura y política en Walsh y Lamborghini. (Para una lectura de Tadeys). En J. Dabove y N. Brizuela (comps.), 
Y todo el resto es literatura. Ensayos sobre Osvaldo Lamborghini (pp. 155181). Buenos Aires: Interzona.

Rosano, S. (2008). El arte como crueldad. En J. Dabove y N. Brizuela (comps.), $Y$ todo el resto es literatura. Ensayos sobre Osvaldo Lamborghini (pp. 201214). Buenos Aires: Interzona. 